\title{
Are fees for cataract surgery still too high?
}

\author{
Cite as: CMAJ 2019 October 28;191:E1202-3. doi: 10.1503/cmaj.1095808
}

Posted on cmajnews.com on Oct. 8, 2019

mprovements in cataract surgery mean the procedure is faster and safer than ever before, allowing ophthalmologists to perform operations more quickly. The rise in productivity has led to increased incomes for surgeons, but has improved efficiency led to lower costs to the health system?

Over the past 30 years, cataract surgery has undergone huge advances. Dr. Guillermo Rocha, an ophthalmologist in Manitoba, recalls that his first surgery, in 1990 , required a $10 \mathrm{~mm}$ incision to remove the cataract and replace the lens, followed by sutures. Now he makes an incision smaller than $2 \mathrm{~mm}$, sometimes using a laser, destroys the cataract using ultrasound, inserts a folding lens, and allows the incision to heal on its own.

New technologies and techniques have transformed the operation from an inpatient procedure requiring months of recovery and follow-up to an outpatient one that allows patients to return to their normal lives within days. "I have operated on surgeons that have then gone back to work the same day," says Rocha.

Rocha estimates that he can handle around twice as many cases each day than when he started. But more importantly, the safety, effectiveness and predictability of the surgery have also increased substantially.

Improved productivity for ophthalmologists has led to increased incomes, as they are able to bill for more procedures each year. Reports in Ontario that ophthalmologists make up a disproportionate number of the highest-billing doctors in the province, including 9 of the top 20, have led to calls for the fee for the procedure to be reduced.

Arthur Sweetman, a health care economist at McMaster University, says when productivity improves, prices generally come down. But the issue is more com- plicated in health care because the groups paying for medical procedures, provincial governments, do not usually set prices directly. Instead, governments negotiate collective agreements with provincial medical associations that typically include an average increase for all fees for medical services provided by physicians. The associations decide how to distribute the overall increase in money between medical specialties.

That has led to contentious "relativity" debates with suggestions that some specialists are overpaid and others underpaid for equal amounts of work. Such disputes within the Ontario Medical Association (OMA), and between the OMA and the Ontario government, plagued recent contract negotiations for doctors. Ophthalmology was one of the specialist groups in
Ontario that voted to break away from the OMA and form a separate association for specialists last year.

"The reason for the debate on relativity is that some specialists have recouped most of the financial gains from improved productivity, and not passed them on to the consumer," says Sweetman. "There is a sense that the benefits have accrued to the practitioners rather than the patients."

Ophthalmologists say many of the improvements in cataract surgery are the result of new, high-tech equipment, such as femtosecond lasers and optical biometry machines, which are expensive and require frequent updating and training. The biometry machines used to measure the eye, for example, are usually replaced with newer, upgraded versions every five years or so.

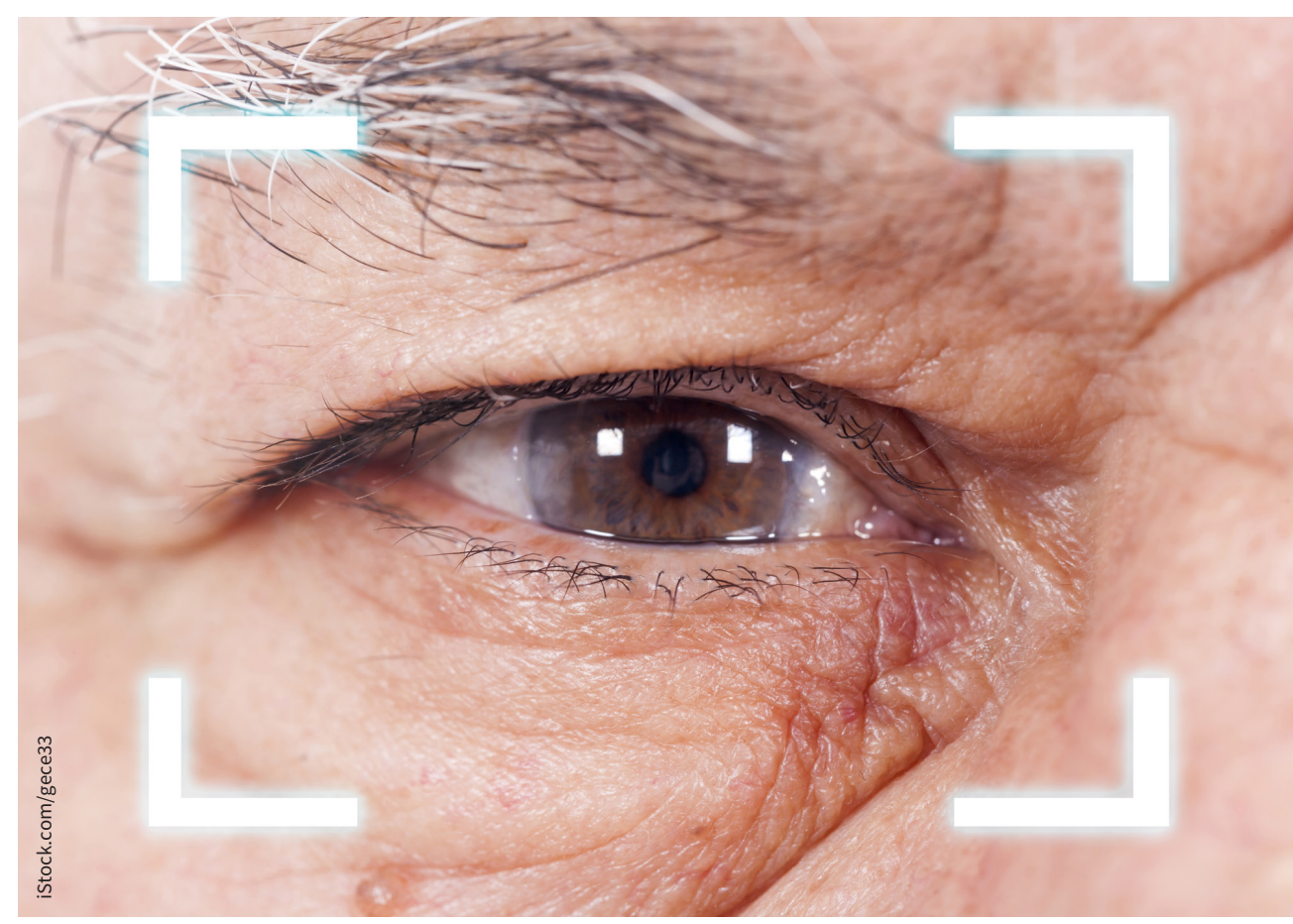

Technology costs have risen for ophthalmologists who perform cataract surgeries, but so have efficiency, productivity and surgeon incomes. 
And much of that added cost in technology falls on surgeons, says Rocha, as it is used in their offices, not the hospital. "To get to this level of efficiency has taken a lot of advances in technology, education and skills," he says. "It takes a lot to make it look easy under the microscope."

The negotiated fees paid to ophthalmologists for cataract surgery hover around $\$ 400$ across the country, but they have been falling. Rocha says the fee in Manitoba has decreased by about $10 \%$ over the past 20 years, while fees in Ontario have fallen by $25 \%$. Cuts like these will hurt recruitment and retention of doctors, he says.

Sweetman says that although technology costs have risen, productivity appears to have increased faster, so even the reduced fees are probably still too high. And he doubts the costs are too high for surgeons to bear. "I suspect that if the costs were too high relative to their pay, they would give numbers to back that up."

Brian Owens, St. Stephen, NB 